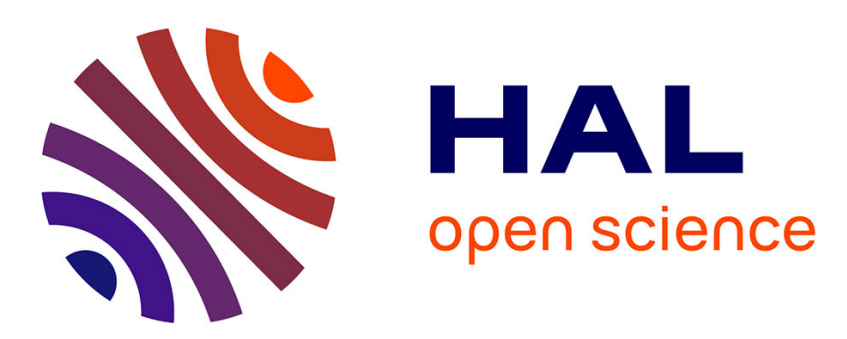

\title{
Carbon Leakage and Capacity-Based Allocations. Is the EU right?
}

Guy Meunier, Jean-Pierre Ponssard, Philippe Quirion

\section{To cite this version:}

Guy Meunier, Jean-Pierre Ponssard, Philippe Quirion. Carbon Leakage and Capacity-Based Allocations. Is the EU right?. 2014. hal-00672907v3

\section{HAL Id: hal-00672907 https://hal.science/hal-00672907v3}

Preprint submitted on 14 May 2014

HAL is a multi-disciplinary open access archive for the deposit and dissemination of scientific research documents, whether they are published or not. The documents may come from teaching and research institutions in France or abroad, or from public or private research centers.
L'archive ouverte pluridisciplinaire HAL, est destinée au dépôt et à la diffusion de documents scientifiques de niveau recherche, publiés ou non, émanant des établissements d'enseignement et de recherche français ou étrangers, des laboratoires publics ou privés. 
CARBON LEAKAGE AND CAPACITY-BASED ALLOCATIONS. IS THE EU RIGHT?

\author{
Guy MEUNIER \\ Jean-Pierre PONSSARD \\ Philippe QUIRION
}

(Revised version 2012-36)

Cahier $n^{\circ}$ 2014-13

\title{
DEPARTEMENT D'ECONOMIE
}

Route de Saclay

91128 PALAISEAU CEDEX

(33) 169333033

http://www.economie.polytechnique.edu/

mailto:chantal.poujouly@polytechnique.edu 


\title{
Carbon Leakage and Capacity-Based Allocations.
}

\section{Is the EU right? *}

\author{
Guy Meunier ${ }^{1,2}$, Jean-Pierre Ponssard ${ }^{2}$ and Philippe Quirion ${ }^{3}$ \\ ${ }^{1}$ INRA-UR1303 ALISS, 65 bd de Brandebourg 94205 Ivry-sur-Seine \\ ${ }^{2}$ CNRS-Ecole Polytechnique, route de Saclay, 91128 Palaiseau \\ ${ }^{3}$ CNRS-CIRED, 45 bis av. de la Belle Gabrielle, 94736 Nogent-sur-Marne
}

April 2014

\begin{abstract}
Competitiveness and carbon leakage are major concerns for the design of $\mathrm{CO}_{2}$ emissions permits markets. In absence of a global carbon tax and of border carbon adjustments, output based allocation is a third best solution and is actually implemented (Australia, California, New Zealand). The EU has followed a different route; free allowances are allocated to existing or new capacities in proportion to a benchmark independent of actual production. This paper compares these two schemes and shows that the optimal one is actually a combination of both schemes, or output based allocation alone if uncertainty is limited. A key assumption of our analysis is that the short term import pressure depends both on the existing capacities and the level of demand, which is typical in capital intensive and internationally traded sectors. A calibration of
\end{abstract}

${ }^{*}$ We thank Sean Healy, Katja Schumacher (Öko-Institut), Denis Ellerman, Karsten Neuhoff and Christina Hood for useful discussions and comments on an earlier draft. 
the model is used to discuss the EU scheme for the cement sector in the third phase of the EU-ETS (2013-2020). This allows for a quantification of various policies in terms of welfare, investment, production, firms profits, public revenues and leakage.

. JEL Classification: D24, L13, H23, L74

Keywords: cap and trade, output based allocation, subsidization of capacity, climate policy, carbon leakage, competitiveness.

\section{Introduction}

Nowadays a number of countries have set up their own national or regional Emission Trading Scheme (ETS) or ambition to do so (Australia, California, China, India, New Zealand...). The EU implemented its ETS in 2005 and has significantly revised the allocation rule for the period 2013-2020. In all these designs, the allocation mechanism has been or will be an important factor of success for their actual implementation.11 This attention comes from competitiveness and leakage issues and their implications in terms of potential profit loss, employment, reduced environmental impact due to the transfer of emissions from one country to the other.

Indeed, the implementation or the lack of implementation of these national ETS will generate major differences in the carbon prices worldwide. Internationally traded carbon intensive sectors may be significantly affected by these differences resulting in production and investment transfers from high carbon price countries to low carbon price ones. While border adjustment mechanism may limit these competitive distortions, they are seen by many emerging countries as indirect protectionist measures incompatible with the philosophy of the World Trade Organization (Wooders and Cosbey, 2010).

The main approach to circumvent this political constraint relies on "output based" al-

\footnotetext{
${ }^{1}$ See Hood, 2010 for a review of existing and proposed ETS worldwide, and a presentation of their respective design.
} 
location (implemented in New Zealand and California, and to be implemented in Australia if the new majority does not repeal the "Clean Energy Future legislation"). The EU has followed a different route, free allowances are allocated to existing capacities and new capacities based on an industry benchmark, but without reference to actual production, we refer to this scheme as "capacity based" allocation. This paper compares these two schemes. A major ingredient in the comparison refers to the fact that the scheme is designed ex-ante for a number of years over which economic conditions may vary. We show that when uncertainty is large the socially optimal policy is a combination of output and capacity based allocation, while output based allocation alone is optimal if uncertainty is limited. By "socially optimal", we mean the third-best policy, assuming that neither a global carbon tax nor border carbon adjustment is feasible.

More precisely, we consider a homogeneous good produced competitively with either home or foreign plants, both productions emit pollutant emissions. Firms can invest in a fixed input, capacity, to reduce the home production cost. The home production is subject to an environmental regulation whereas imports are not regulated. If emissions from home production are taxed but not the emissions from imports this asymmetry of regulation creates a positive externality, an increase in the home production having a positive environmental effect via the reduction of imports. The positive externality associated with leakage calls for a subsidy on home production additional to the tax on emissions. This is the rationale for the output based rule of free allocation.

The precise value of the optimal production subsidy is related to the output demand and if this demand is random or variable but the subsidy fixed, the use of a complementary policy could be justified. A subsidy on capacity (i.e. capacity based allocation) could be justified to discriminate among demand states. A necessary condition for this result is that new capacity has a stronger influence on home production when demand is large and leakage occurs than when demand is low and leakage does not occur. This condition may be expected 
to hold in a number of energy intensive and trade exposed sectors. Such sectors are typically capital intensive, capacity decisions are planned over long time horizons, so that capacity constraints and short term demand levels significantly influence the level of imports.

It is well known that output based allocation has two positive impacts and a negative one. Firstly abatement incentives remain, secondly by reducing the perceived cost of home production it preserves a level playing field with foreign production unaffected by a carbon price. However, these positive impacts are obtained at the cost of eliminating the output price signal for consumers so that there is be excessive consumption of products that benefit from the scheme. The introduction of a social welfare function allows to balance between positive and negative impacts. This is particularly relevant if in some states of the world leakage is low so that the regulator would like to have the carbon price signal for consumers in those states. This calls for a reduction of the production subsidy. If a capacity subsidy does not affect the home production in case of low demand and reduce leakage in case of high demand, this will increase the benefits of lowering the production subsidy. However, investment subsidy has its own negative impact, it encourages over capacity.

Several authors have analyzed output-based allocation scheme. Quirion (2009) provides an early survey of this literature. Böhringer and Lange (2005) discuss its advantages compared to an emissions-based allocation rule. Böhringer et al. (2010) and Böhringer et al. (2012) compare it to border tax adjustments and industry exemptions. Fischer and Fox (2012) and Holland (2012) analyze its effectiveness to address the issues of leakage and competitiveness. Uncertainty is not discussed in these papers.

Capacity based allocation has received much less attention in the literature. It is related to the question of reserves for new entrants. The economics of such a scheme has firstly been investigated by Ellerman (2008) in the context of the EU electricity market. The analysis points out that it may have resulted in excess investment in carbon intensive electricity production. Ellerman also discusses the possible impact of this excessive investment for 
the electricity price giving due consideration to peak and off peak periods. Other authors have also discussed how the EU allocation mechanism has influenced the energy mix in the electricity industry (see Neuhoff et al. 2006, Zhao et al. 2010, Golombeck et al., 2013).

In our model the demand function and the home productive capacity determine imports, while the home productive capacity is endogenously determined prior to knowing the actual demand but knowing the climate policy. Meunier and Ponssard (2014) consider how, in such a setting, the introduction of a carbon tax at home influences the short-term (without capacity adjustment) and long-term leakage (with capacity adjustment). In this paper we show that output based and capacity based allocation schemes are complementary instruments to maximize social welfare. The idea to distinguish between short term and long term effects has been recognized in the applied literature (see Ellerman et al. 2010) but remains so far rarely made explicit in the welfare analysis of allocation schemes. One notable exception is Fowlie et al. (2012) which considers a Markov dynamic oligopoly model. They adopt a normative approach and determine the optimal output-based rule. They focus on the influence of the long-run entry process with imperfect competition while we focus on capacity investment and demand uncertainty.

We apply our model to the case of the cement industry in Europe. The actual allocation scheme is modeled as well as the optimal scheme. With our calibration, it turns out that the optimal scheme is a pure output based scheme, this is so because of the low level of demand uncertainty relative to the high level of existing capacities. We carry on a sensitivity analysis which shows that a combination of instruments may be optimal if regulation could differ among Member States. In coastal Member states the uncertainty relative to existing capacities maybe higher and the international competitive pressure may also be higher due to the accessibility of maritime imports.

Section 2 introduces the model. The optimal regulation is determined in Section 3. Two extensions are also discussed in this section: the possible interaction between the home 
and foreign markets; exogenous versus endogenous emission rates. Section 4 applies our framework to the case of the EU-ETS scheme for 2013-2020 as implemented for the cement sector. A simplified model is used to allow for calibration and a sensitivity analysis. We compare our optimal scheme to the actual one, as well as to other possible scenarios such as a pure auctioning scheme or a border tax adjustment scheme. The respective welfare impacts are derived with the associated levels of investment, production, profit for the firms, public revenues and leakage ratios. In the concluding section we discuss the policy implications of our results for the EU-ETS. We also point out possible extensions for future research.

\section{The model}

Let us consider a homogeneous good, the demand of which is random. The inverse demand function is: $p(q, \theta)$, where $q$ is the total quantity consumed and $\theta$ is a random parameter, with $\mathbb{E} \theta=0,{ }^{2}$ distributed over $[\underline{\theta}, \bar{\theta}]$ according to the cumulative distribution $F$ a continuously differentiable function. The distribution of $\theta$ can represent either risk or time variability of the demand. We assume that $p$ is decreasing with respect to $q$ and increasing with respect to $\theta$. The corresponding consumer gross surplus is $S(q, \theta)$ with $\partial S / \partial q=p(q, \theta)$

There are two technologies to produce this good: a home one and a foreign one. The home production is denoted $q_{h}$ and the foreign production $q_{f}$, so $q=q_{h}+q_{f}$. The foreign production cost is denoted $C_{f}\left(q_{f}\right)$; it is increasing and convex with respect to $q_{f}$. The home production cost is composed of two components: an investment cost relative to the capacity choice and a variable cost to production given the capacity. The investment in a capacity $k$ is proportional to the capacity, $c_{k} k$ in which $c_{k}$ is constant. This investment cost is sunk in the sense that the capacity $k$ is chosen before the demand parameter $\theta$ is known and cannot be modified. The variable cost is $C_{h}\left(q_{h}, k\right)$. We consider that $C_{h}\left(q_{h}, k\right)$ is increasing and

\footnotetext{
${ }^{2}$ The expectation operator is denoted $\mathbb{E}$.
} 
convex with respect to $q_{h}$; it is decreasing and convex with respect to $k$, and the marginal production cost is decreasing with respect to $k$ (the cross derivative is negative).

Home and foreign productions generate polluting emissions at respective constant rates $u_{h}$ and $u_{f}$, the environmental damage is assumed linear with a marginal damage $\sigma$. In a state $\theta$, the welfare is the difference between gross consumer surplus and production cost and environmental damage:

$$
w\left(q_{h}, q_{f}, k, \theta\right)=S(q, \theta)-\left[C_{h}\left(q_{h}, k\right)+C_{f}\left(q_{f}\right)+c_{k} k\right]-\sigma\left[u_{h} q_{h}+u_{f} q_{f}\right]
$$

and, the expected welfare is

$$
W=\mathbb{E}_{\theta}\left[w\left(q_{h}, q_{f}, k, \theta\right)\right]
$$

Environmental damage calls for a regulation of emissions. We assume that home emissions are exogenously priced at $\sigma$, the marginal environmental damage, but that foreign emissions or production cannot be regulated. There is leakage, a decrease in home production decreases direct pollution but has the adverse effect of increasing foreign production and thus creating indirect emissions. This leakage calls for an additional regulation.

For this additional regulation the regulator can only subsidize home production and home capacity. The subsidy on home production is denoted $s_{h}$ and the subsidy on capacity $s_{k}$. We consider a representative price-taking firm. The timing is the following:

- the regulator sets $s_{h}$ and $s_{k}$;

- the firm chooses its capacity $k$;

- $\theta$ is known and the firm decides how much to produce $q_{h}$ and to import $q_{f}$.

Several comments should be made on our setting. First, by considering a representative firm, we implicitly assume that the foreign plants are owned by home producers. This 
assumption is made mainly for a methodological reason. It allows us to focus on the environmental incentive to regulate production and to ignore the "protectionism" incentive to subsidize home production to reduce the price of imports. Second, we do not consider the foreign market and the possible change of the foreign consumption induced by the home regulation. Such a change would indeed affect world emissions and the magnitude of leakage. We implicitly assume that foreign consumption is fixed. We discuss the impact of introducing the foreign market in section 3.2.

Third, the environmental damage is assumed linear, a change of emissions from home or foreign production does not influence the marginal environmental damage. The emissions from the sector under consideration are small compared to total emissions. This is coherent with the partial equilibrium approach used in this paper ${ }^{3}$ Fourth, when interpreting the model in the context of the ETS, the price $\sigma$ should be seen as an exogenous price of emissions permits inferred from the global cap. We suppose that the rates of free allowances per production unit and per capacity, $s_{h} / \sigma$ and $s_{k} / \sigma$, will not affect the price of permits. Again, this supposes that the sector under study is small relative to the scope of the ETS (the emissions of the cement represents approximately a tenth of all ETS emissions). We discuss directions for relaxing this assumption in the conclusion.

\section{Optimal regulation}

\subsection{Base Case}

Let us first describe the market equilibrium. The firm's profit is a function of the market price:

$$
\pi\left(p, q_{h}, q_{f}, k\right)=p q-C_{h}\left(q_{h}, k\right)-\left(\sigma u_{h}-s_{h}\right) q_{h}-C_{f}\left(q_{f}\right)-\left(c_{k}-s_{k}\right) k,
$$

\footnotetext{
${ }^{3}$ Note that Fowlie et al. (2012) make similar assumptions on the marginal environmental cost and ignore the foreign market too.
} 
from the firm's perspective the price $p$ is random, the firm chooses $k$ with a prior distribution of market prices. Then, for each price realization, it chooses the home and foreign productions that maximize its profit (3). The firm's long-term profit is:

$$
\Pi(k)=\mathbb{E}\left[\max _{q_{h}, q_{f}} \pi\left(p, q_{h}, q_{f}, k\right)\right] .
$$

We assume that the firm is price-taker and has rational expectations, its prior distribution of prices corresponds to the long-term equilibrium distribution $p\left(q_{h}+q_{f}, \theta\right)$.

In the short-term, $k$ is fixed and the firm maximizes its profit (3). The price clears the market and the equilibrium productions satisfy the two first order conditions

$$
\begin{aligned}
& p\left(q_{h}+q_{f}, \theta\right)=\sigma u_{h}-s_{h}+\partial C_{h}\left(q_{h}, k\right) / \partial q_{h} \\
& p\left(q_{h}+q_{f}, \theta\right)=\partial C_{f}\left(q_{f}\right) / \partial q_{f}
\end{aligned}
$$

if both quantities $q_{h}$ and $q_{f}$ are strictly positive. The home and foreign equilibrium productions are functions of the demand state $\theta$, the production subsidy $s_{h}$ and the capacity $k$; they are denoted as $q_{h}\left(s_{h}, k, \theta\right)$ and $q_{f}\left(s_{h}, k, \theta\right)$. It will prove useful to consider foreign production as a function of home production and the demand state. Therefore, we denote $\psi_{f}\left(q_{h}, \theta\right)$ the solution of

$$
p\left(q_{h}+\psi_{f}, \theta\right)=\partial C_{f}\left(\psi_{f}\right) / \partial q_{f} .
$$

At the short-term equilibrium $q_{f}\left(s_{h}, k, \theta\right)=\psi_{f}\left(q_{h}, \theta\right)$, this notation emphasizes that the subsidy on home production influences only indirectly foreign production via its effect on home production.

In the long-run, the firm chooses its home capacity by maximizing its long-term profit (4) and anticipating the equilibrium stream of prices. If the equilibrium capacity $k\left(s_{h}, s_{k}\right)$ is strictly positive it satisfies: 


$$
\mathbb{E}\left[-\partial C_{h}(q, k) / \partial k\right]=c_{k}-s_{k} .
$$

The marginal cost of a capacity is equalized with the expected short-term marginal benefit from a cost reduction. The capacity is null if

$$
\mathbb{E}\left[-\partial C_{h}(q, 0) / \partial k\right]<c_{k}-s_{k} .
$$

The regulator objectives is to maximize the welfare function given by equations (1) and (2). First, the standard result hold:

Lemma 1 If it is feasible, Welfare is maximized by taxing home and foreign emissions by $\sigma$.

Proof. From the expression of welfare (2), a tax $\sigma$ on home and foreign emissions would ensure that the first order conditions of (price-taking) firms' profit maximization coincide with the first order conditions of welfare maximization, for any given $k$ in all states $\theta$. Therefore, for any $k$ the productions would be optimal. And the $k$ chosen by the firm would satisfy (8) with $s_{k}=0$, which would also be satisfied by the optimal $k$, and by uniqueness the two would be equal.

From now on we assume that foreign emissions or production can neither be directly regulated through a global carbon tax nor through a border adjustment tax. In the remaining part of the paper, and for simplicity, we shall refer to "optimal" for the second best policy whenever neither a global carbon tax nor border carbon adjustment is feasible. The environmental cost $\sigma u_{f} q_{f}$ is not internalized by producers. In such a case, there is a positive externality from home production that comes from the reduction of foreign emissions; it partially offsets the negative externality due to domestic emissions. 
Proposition 1 The optimal couple of subsidies $s_{h}, s_{k}$ satisfies:

$$
\begin{aligned}
& s_{h}=\sigma u_{f} \frac{-\mathbb{E}\left[\frac{\partial \psi_{f}}{\partial q_{h}} \frac{\partial q_{h}}{\partial s_{h}}\right]}{\mathbb{E}\left[\frac{\partial q_{h}}{\partial s_{h}}\right]} \\
& s_{k}=\sigma u_{f} \mathbb{E}\left[-\frac{\partial \psi_{f}}{\partial q_{h}} \frac{\partial q_{h}}{\partial k}\right]-s_{h} \mathbb{E}\left[\frac{\partial q_{h}}{\partial k}\right] .
\end{aligned}
$$

The proof is in Appendix A. The regulator has to set a positive production subsidy to limit leakage. The sign of the capacity subsidy is ambiguous and depends on the comparison of two terms. Before further analyzing these two instruments and the role played by uncertainty, it is worth considering the benchmark situation without uncertainty.

Corollary 1 Without uncertainty, the production subsidy satisfies

$$
s_{h}=-\sigma u_{f} \frac{\partial \psi_{f}}{\partial q_{h}}
$$

and the capacity subsidy is null.

Proof. From the equations of Proposition 1, without uncertainty, equation (10) gives (12); and plugging this equation into (11) gives $s_{k}=0$.

Without uncertainty there is no need to subsidize capacity, the subsidy of production is sufficient. The right-hand side of 12 is the marginal benefit from an increase in home production. This marginal benefit is the product of three factors: the marginal cost of emissions $\sigma$, the foreign emissions rates $u_{f}$ and the sensitivity of foreign production to home production $\partial \psi_{f} / \partial q_{h}$. With this subsidy the positive externality from home production is internalized by the firm and there is no need to further subsidize capacity.

With uncertainty the situation is different. The sensitivity of foreign production to home production depends upon the demand state. Consequently, the regulator would like to set 
a subsidy on production conditional on the demand state $\theta$. If the regulator could set a subsidy $s_{h}(\theta)$ in each demand state similar to $(12)$, there would be no need to subsidize capacity.

\subsection{Extensions}

The model was kept at a minimal level of complexity to get our result. A subsidy on capacity might be justified if demand is random and the regulator can neither tax foreign emissions nor discriminate among demand states. Several natural extensions are discussed: i) the explicit modelling of the foreign market and the role of exports and ii) the variation of the emission rate and the optimal emission price.

\section{Foreign market}

The increase of imports from a foreign market has an impact on the foreign market equilibrium, in particular foreign consumption might be reduced because of an increase of the foreign price. This adjustment of foreign consumption has an impact on pollutant emissions and a natural question is whether the analysis would be modified by considering this adjustment.

The foreign market could be modeled by introducing the foreign consumers' demand and surplus. The relevant welfare function, for our analysis, would encompass the welfare of the foreign consumers. The analytical results would be similar, Proposition 1 would still hold with the difference that $\psi_{f}$ would be the total foreign production instead of the quantity imported. Indeed, what matters for the analysis of leakage is the effect of home production on unregulated foreign emissions, and the rationale for capacity subsidies does not depend on the precise channel through which both are linked.

With a foreign market, the sensitivity of foreign production to home production would be smoothed by the adjustment of the foreign demand function. Consider two extreme cases: On 
the one hand if the quantity imported from the foreign market is simply subtracted from the foreign consumption, as would be the case with an infinitely elastic foreign demand, leakage would be nil and the rationale for either subsidy would be canceled. On the other hand consider a situation in which the quantity imported does not reduce foreign consumption and directly increases world emissions. In such a case the foreign price would be constant and cost convexity could originate from the convexity of the transport costs. For the cement market considered in the numerical illustration, this latter situation is the relevant one since imports mainly originate from idle foreign coastal plants (Demailly and Quirion, 2005).

The possibility to export could also be introduced in the framework, and would not modify the formula of Proposition 1 with $\psi_{f}$ being the foreign total production. Exports would occur when the home demand is low and the foreign demand is large, and imports in reverse situations, no trade would occur in intermediate situations. Indeed, leakage also occurs through the reduction of exports. If firms export in low home demand states, the discriminatory role of capacity subsidy is reduced. If capacity has a larger influence on production the higher the production is, the capacity subsidy would be relatively ineffective to reduce leakage in low demand states in which exports occur but home production is low.

A more complete model would represent $N$ interconnected markets with local demand and production facilities. The demand on each market would be random and a subset of the markets would be regulated. Trade would originate from uncertainties and take place to correct for the local disequilibria between supply and demand. This extension is left for future research.

\section{Emission price and the emission rate}

We have assumed that the emission price was fixed, equal to the marginal environmental damage, and not endogenously determined by the regulator simultaneously with the couple of subsidies. A question is whether leakage would justify the implementation of an emis- 
sion price different than the Pigouvian level. The answer to this question depends on the assumption made on the emission rate.

The emissions rate $u_{h}$ was assumed constant, it does not vary with production and could not be chosen by the firm. With an exogenous carbon price equal to the marginal environmental damage, relaxing either assumption would not modify the analysis. This is reflected in the fact that $u_{h}$ does not enter the formula obtained. With a carbon price equal to the marginal environmental damage, the direct environmental externality is correctly internalized by firms and the emission rate would be efficiently chosen if such a choice were introduced. The subsidies are used to correct the leakage externality caused by home production and not home emission.

If the carbon price were chosen by the regulator, it could be welfare enhancing to distort the carbon price away from the Pigouvian value if the emissions rate varies with production, whether it is endogenously set or not. The rationale for such a distortion would be similar to the rationale for the capacity subsidy: it could be a way to complement the subsidy on production by indirectly discriminating among demand states. Such a discrimination would be effective if the carbon price has, in some demand states, an effect on production different from the effect of the subsidy, and this is only possible if the emission rate varies with the production.

In the numerical illustration, firms will be able to choose their emission rate. However, the cost to reduce the emission rate will be assumed proportional to the quantity produced, an assumption which implies that the emission rate is independent of production. 


\section{A numerical application to the European cement mar- ket}

In this section, the model is applied to the EU cement sector. $4^{4}$ We chose this sector because it features one of the highest $\mathrm{CO}_{2}$ /value added ratios (Hourcade et al., 2007), had the highest emissions of all the manufacturing industry sectors covered by the EU-ETS in phase 1 (20052007; cf. Kettner et al., 2008) and features large demand variations. We use a simplified specification of the model which allows for the explicit derivation of the optimal scheme. We abstract from some features of the cement market, such as imperfect competition within the EU, exports from the EU and geographic differentiation. We shall come back to the possible role of these features in the concluding section.

\subsection{A simplified linear quadratic specification}

The demand is assumed linear with an additive uncertainty, $p(q, \theta)=a+\theta-b q$. Home production can be performed with new and old plants. The old plants have various variable costs depending on their age, the older plants being more expensive than the more recent ones. The cost of these old plants is $c_{h} q_{o}+0.5 \gamma_{h} q_{o}^{2}$ in which $q_{o}$ denotes the production from old plants. The new plants have to be built. The cost of a new capacity is $c_{k}$ and the variable cost of the new capacity is $c_{h}$. With these assumptions, the variable cost of home production is:

$$
C_{h}(q, k)= \begin{cases}c_{h} q & \text { if } q<k \\ c_{h} q+0.5 \gamma_{h}(q-k)^{2} & \text { otherwise }\end{cases}
$$

\footnotetext{
${ }^{4}$ More precisely, to the EU grey clinker market excluding white cement, which refers to a different production process and a different market.
} 
New and old plants have identical emissions rates $u_{h} !^{5}$ This emission rate is the result of an optimization procedure: $c_{h}$ is a decreasing function of the emission rate $u_{h}$ (a more pollutant production process is less costly) and the optimal emissions rate $u_{h}$ is the solution of $\sigma=-c_{h}^{\prime}\left(u_{h}\right)$. In that case the emissions rate is solely determined by the price of emissions. Concerning the foreign production, we also consider a quadratic form, i.e.,

$$
C_{f}\left(q_{f}\right)=c_{f} q_{f}+0.5 \gamma_{f} q_{f}^{2}
$$

It is further assumed that in the situations considered, the price of emissions and the subsidy on production satisfy:

$$
c_{f}>c_{h}+\sigma u_{h}-s_{h}
$$

the variable cost of home production with a new capacity is lower than the marginal cost of the first unit imported.

We consider a binary distribution of the demand states $\theta=\theta^{+}$with probability $\lambda$ and $\theta=\theta^{-}$with probability $1-\lambda$, with $\theta^{-}<\theta^{+}$and $\lambda \in(0,1)$. For leakage to occur there should be imports at least in the high demand state $\theta^{+}$. The import cost $c_{f}$ should be sufficiently low to ensure that it is the case. Consequently, there are three possible situations depending on the type of marginal plants in the low demand state. The three situations are depicted Figure 1. Either the firm produces less than its new capacity $(1(\mathrm{a})$, or it produces more

\footnotetext{
${ }^{5} \mathrm{~A}$ recent study on abatement in the cement industry in the EU shows that two factors play a role: fuel mix and thermal energy efficiency of the kiln. New plants do have higher energy efficiency than older ones, but only by a few percentage points, except compared to the very old kilns relying on the so-called "wet" technology, which currently only produce $5 \%$ of clinker in the EU (Neuhoff et al., 2014, Table 1). The "semi-wet" technology, which accounts for $7 \%$ of clinker in the EU, is only $9 \%$ less energy-efficient, and the other plants are only a few points below the newest ones in terms of energy efficiency. Moreover, the fuel mix is often less carbon-intensive in old plants. As a consequence, plants with the lowest emissions per ton of clinker are not the most energy efficient, as the European cement association Cembureau has shown on the basis of an individual plants database (Ecofys, 2009, p. 16). The second factor may depend on investment since the more recent the kiln the higher the efficiency. However the global impact is not so clear since older plants may provide higher opportunities for abatement with respect to the other factor (Neuhoff et al., 2014). For simplicity Because this database is not public, we cannot estimate the difference between new and existing plants as regards specific emissions, so we consider in our model that investment has no influence on abatement policy.
} 
and does not import $1(\mathrm{~b})$, or it imports $1(\mathrm{c})$.
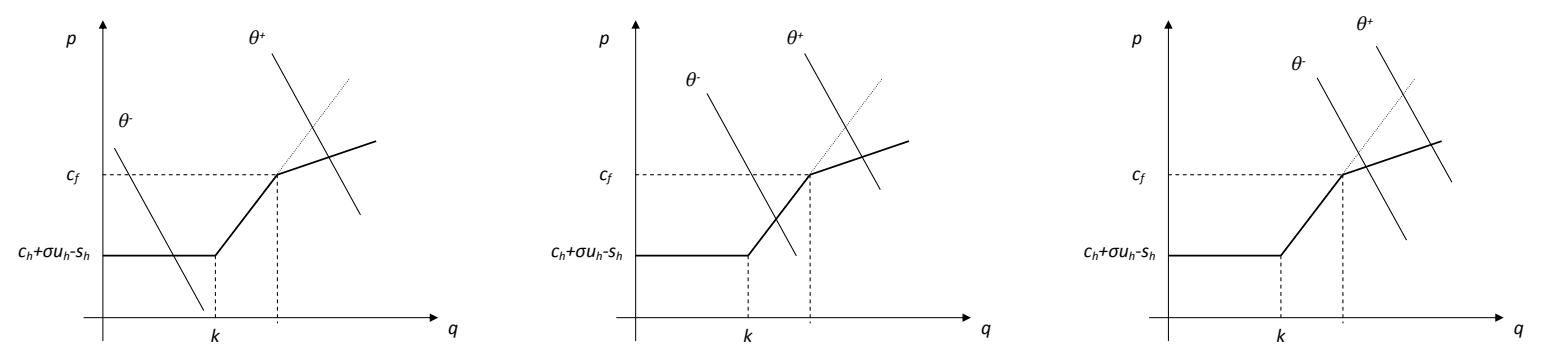

(a) Case A: excess capacity in the (b) Case B: full capacity but no (c) Case C: imports in both states low demand state. import in the low demand state.

Figure 1: The three possible outcomes for the short-term equilibrium with a binary distribution.

Note that the optimal regulation and the type of situation are simultaneously determined.

Corollary 2 The optimal subsidies are:

Case A: If there is excess capacity in the low demand state then:

$$
\begin{aligned}
& s_{h}=\sigma u_{f} \frac{b}{b+\gamma_{f}} \frac{\lambda}{\lambda+(1-\lambda) R_{A}} \text { and } s_{k}=(1-\lambda) s_{h} \frac{\gamma_{h}}{b} \\
& \text { where } R_{A}=\left(\gamma_{h}+b \frac{\gamma_{f}}{b+\gamma_{f}}\right) \frac{1}{b}
\end{aligned}
$$

Case B: If all new capacity is used but there is no import in the low demand state then:

$$
\begin{aligned}
& s_{h}=\sigma u_{f} \frac{b}{b+\gamma_{f}} \frac{\lambda}{\lambda+(1-\lambda) R_{B}} \text { and } s_{k}=0 \\
& \text { where } R_{B}=\left(\gamma_{h}+b \frac{\gamma_{f}}{b+\gamma_{f}}\right) \frac{1}{b+\gamma_{h}}
\end{aligned}
$$

Case $C$ : If there are imports in the low demand state then:

$$
s_{h}=\sigma u_{f} \frac{b}{b+\gamma_{f}} \text { and } s_{k}=0
$$


The proof is in Appendix (B). A positive capacity subsidy should be implemented only if the new capacity is not fully used in the low demand state (case A). In that case, an increase of capacity does not influence home production in the low demand state whereas the production subsidy does. The production subsidy is distortive in these states whereas the capacity subsidy is not. In the other two cases, whether or not imports occur in the low demand states, the capacity should be null because of a particular feature of the linear specification. With this specification, the influence of capacity on production in the low and the high demand states is proportional to the influence of the subsidy on production (the proportion being $\gamma_{h}$ ). Therefore, the capacity subsidy does not have a higher discriminatory effect than the production subsidy and the optimal capacity subsidy is null. This feature might not hold with other specifications. ${ }^{6}$

Let now look more closely at the expressions of the optimal subsidies in each case. In case C, imports always occur, and the linearity of our framework implies that the situation is similar to a situation without uncertainty. It happens when the range of uncertainty $\theta^{+}-\theta^{-}$ and the import cost $c_{f}$ are relatively small. In that case the optimal subsidy is equal to the optimal subsidy without uncertainty. It is the product of the marginal environmental damage, the foreign emission rate and the sensitivity of imports to the home production.

In cases $\mathrm{A}$ and $\mathrm{B}$, imports only occur in the high demand state and the production subsidy is distortive in the low demand state. The optimal production subsidy is therefore lower than the no-uncertainty subsidy. Compared to the no-uncertainty subsidy, there is an additional factor in both cases A and B. This additional factor is the ratio between the expected effect of the subsidy on production in the high demand states (in which imports occur) and the expected effect of the subsidy on production in all demand states. The latter ratio can be interpreted as a measure of the efficiency of the subsidy. In case B the subsidy

\footnotetext{
${ }^{6}$ For instance if $C\left(q_{h}, k\right)=q_{h}^{2} / k$ the effect of capacity on production would be increasing with respect to the demand state while the effect of the subsidy would be constant and a capacity subsidy could be justified even if imports always occur.
} 
is larger than in case $\mathrm{A}\left(R_{A}>R_{B}\right)$. In Case $\mathrm{B}$ old plants are used, and the convexity of their cost tends to soften the negative influence of the subsidy on production $\left(1 /\left(b+\gamma_{h}\right)\right)$. Therefore, the inefficiency of the subsidy in low demand states is lower in case B than in case A.

It is worth stressing that if the emissions rates of imports and of home production are close, the optimal rate of free allocation $\left(s_{h} / \sigma\right)$ should be lower than $u_{h}$, which corresponds to a full recycling of permits (for the sector considered). It would be lower for two reasons: because the sensitivity of imports to home production is lower than unity $\left(\gamma_{f}>0\right)$, and because imports might not occur in all demand states.

\subsection{Calibration of the simplified specification and a preliminary exploration}

The calibration is detailed in Appendix B.3. Table 1 summarizes the main parameters.

\begin{tabular}{|l|c|}
\hline \multicolumn{1}{|c|}{ Parameter } & Value \\
\hline Expected demand curve intercept $(\mathrm{a})$ & $170 € / \mathrm{t}$ \\
\hline Additive uncertainty $\left(\theta^{+} \& \theta^{-}\right)$ & $+/-35 € / \mathrm{t}$ \\
\hline Probability of the high demand state $(\lambda)$ & $1 / 2$ \\
\hline demand curve slope $(b)$ & $0.5(€ / \mathrm{t}) / \mathrm{t}$ \\
\hline Annualized fixed cost of capacity $\left(c_{k}\right)$ & $45 € / \mathrm{t}$ \\
\hline $\begin{array}{l}\text { Operational cost of new plants } \\
\text { and of the least costly existing plant }\left(c_{h}\right)\end{array}$ & $25 € / \mathrm{t}$ \\
\hline price of cheapest import $\left(c_{f}\right)$ & $50 € / \mathrm{t}$ \\
\hline Slope of existing plants supply curve $\left(\gamma_{h}\right)$ & $.25 € / \mathrm{t} / \mathrm{Mt})$ \\
\hline Slope of imports supply curve $\left(\gamma_{f}\right)$ & $1 € / \mathrm{t} / \mathrm{Mt} /)$ \\
\hline CO ${ }_{2}$ price $(\sigma)$ & $20 € / \mathrm{t})$ \\
\hline Benchmark for EU free allocation & $766 \mathrm{~kg} \mathrm{CO}_{2} / \mathrm{t}$ \\
\hline Specific emissions home $\left(u_{h}\right)$ & $758 \mathrm{~kg} \mathrm{CO}_{2} / \mathrm{t}$ \\
\hline Specific emissions foreign $\left(u_{f}\right)$ & $852 \mathrm{~kg} \mathrm{CO}_{2} / \mathrm{t}$ \\
\hline
\end{tabular}

Table 1: Calibration of the simplified specification

Based on this calibration Corollary 2 gives the corresponding optimal policy. It turns out 
that we are in Case C, i.e. the situation is similar to a situation without uncertainty. This is obviously a special case. It comes from the fact that in spite of the wide variations in the EU activity level between 2007 and 2009, the level of the EU imports relative to the EU demand remained relatively low. To get a more comprehensive understanding of our modeling we now provide a simulation over an extended range of parameters which may correspond the the situation that occurred in some Member States. This will also allow to put this extreme case in a broader perspective.

Consider two sets of values for $\gamma_{h}$ and $\gamma_{f}$, namely the one used in the calibration, $\gamma_{h}=0.25$ and $\gamma_{f}=1$, and another set in which $\gamma_{h}=4$ and $\gamma_{f}=0.25$. In this latter set the marginal cost for old plants is steeper, reflecting stronger capacity constraints in old plants, and the marginal import cost is lower, reflecting easier access to sea-haul imports. Hold constant the demand state $\theta^{+}$and decrease $\theta^{-}$so that the situation corresponds to case A. Let now the parameter $\lambda$ vary in $(0,1)$. When $\lambda=1$ the situation corresponds to a situation without uncertainty, which as proved in corollary 2 gives similar results as in Case C. When the situation corresponds to Case A Figure (2) depicts the optimal policies as a function of $\lambda$ for the two couples of cost slopes. $]^{7}$ In both Figures $2(\mathrm{a})$ and $2(\mathrm{~b})$ the optimal policy remains a combination of output and capacity based except at the extreme when there is no longer any uncertainty. The output based subsidy is always increasing with $\lambda$; this makes sense because the less likely the imports, the more distortive subsidizing domestic production. The capacity based subsidy is bell shaped with $\lambda$; this also makes sense because there are two conflicting factors, for low values of $\lambda$, the social benefit of subsidizing investment is low because the leakage is small, whereas for high values it is low because one would prefer to directly subsidize domestic production.

Comparing the two Figures delivers an interesting message. If the marginal import cost

\footnotetext{
${ }^{7}$ Detailed calculations show that when $\lambda$ goes to zero Case A can no longer exist, the situation would move to Case B and Case $\mathrm{C}$ through corner solutions and the optimal policy needs to be adapted accordingly.
} 
is relatively steep (as it is the case with our calibration) imports almost auto-regulate. The optimal level of free allocations, either capacity or output based, significantly decreases. This comes from the fact that our objective is not to reduce leakage as such but to maximize social welfare, with a balance between the benefit of the price signal and the cost of leakage. This point is overlooked in most discussions. For instance, Fischer and Fox (2012) analyze an output based scheme which would correspond to $s_{h}=\sigma u_{h}$. However, Fowlie et al. (2012) do consider a similar welfare function as in this paper and also get a lower rate for an output based policy due to an import competitive fringe with a linear supply curve.

This sensitivity analysis suggests stronger leakage protection measures for coastal areas than in landlocked areas (a point also mentioned in Fowlie et al. (2012)). Indeed the data associated to Figure 2(a) may correspond to a coastal member State such as Spain, which faced large construction booms followed by extreme recessions, and for which we can imagine that the two parameters $\gamma_{h}$ and $\gamma_{f}$ would be close to those used in Figure $(2(\mathrm{a})]$. Designing instruments that take into account this important geographic characteristics of the industry at the European level would be quite challenging, and could open the door to intra-EU competition distortions. Allocation rules differed across member states in the first two phases of the EU ETS (2005-2012), and the fear of competition distortions motivated the harmonized allocation rules that the EU adopted for 2013 onwards. Nevertheless, this would be an interesting policy question to pursue. 


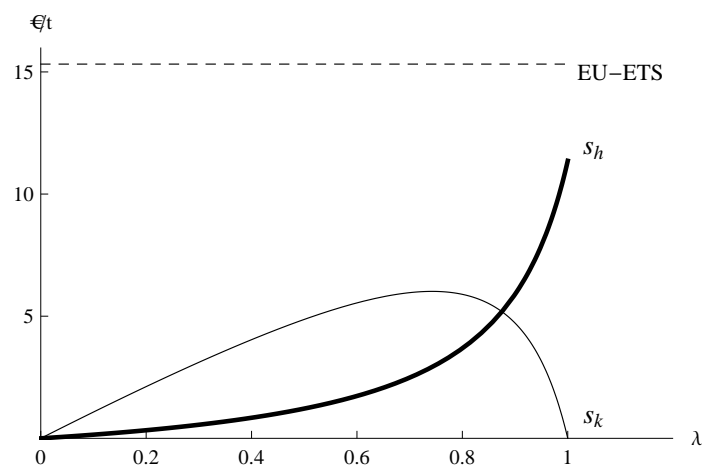

(a) The optimal policy for $\gamma_{h}=2$ and $\gamma_{f}=0$.

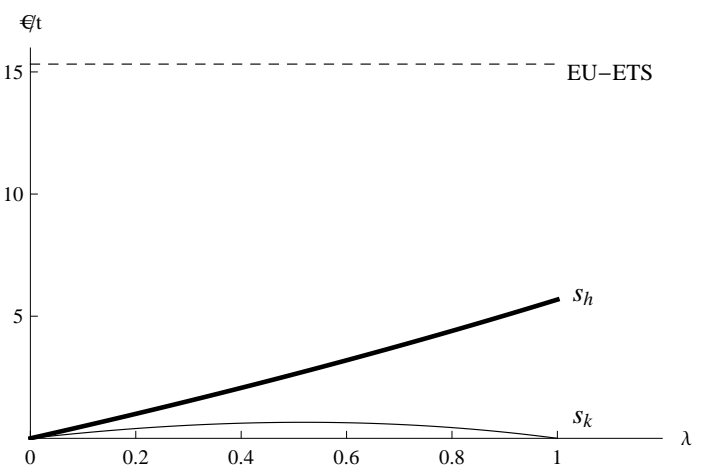

(b) The optimal policy for $\gamma_{h}=0.25$ and $\gamma_{f}=$ 1.

Figure 2: The influence of the probability of the high demand state, $\lambda$, on the optimal policy. The rate $E U-E T S$ corresponds to the actual level implemented in the EU-ETS.

\subsection{The allocation mechanism in the EU-ETS for 2013-2020 in the cement sector 8}

In December 2008, major changes to the EU-ETS were decided, which apply from 2013 onwards (phase III of the EU-ETS). In particular, a majority of allowances are now auctioned. However, sectors deemed at risk of carbon leakage (including clinker manufacturing) continue to receive free allowances. Every year, the operator of installations in these sectors receives a number of allowances equal to a benchmark times an activity level. The clinker benchmark equals $766 \mathrm{~kg} \mathrm{CO} /$ t. clinker; it was calculated as the average specific emissions of the $10 \%$ most CO2-efficient clinker kilns in the EU.

We want to simulate the impact of the phase III design in a future economic context experiencing a range of uncertainty similar to the one observed in the recent past. The calibration of the model is made using the past data (2007-2009), assuming that the climate policy in phases I and II had no influence on the firms decisions. The details of this calibration are given in appendix B.

\footnotetext{
${ }^{8}$ This section is largely based on Quirion et al. (2012).
} 
In our simulation the phase III policy is modelled as follows. For existing installations, the activity level is the installation's historic production expressed as the median of the years 2005-08 or 2009-10, whichever is higher. Using Table 1, old plants will receive a credit allowances of $15 €\left(20 € / \mathrm{tCO}_{2} \times 0.766 \mathrm{tCO}_{2} /\right.$ tclinker $)$ per unit of 2007 production.

In order to ensure that free allowances are not allocated to installations which have subsequently ceased operation, the Directive states that no allowance will be allocated to installations that have stopped operating. In the event that an installation has only partially ceased operations, specific thresholds determine the number of emission allowances that should be allocated to such an installation. However, if the activity level of an installation does not drop below $50 \%$ of the initial activity level, the installation will still receive $100 \%$ of its allocation. Thus, it is unlikely that this "closure rule" will have a significant impact, because operators have an incentive to reduce production homogeneously in their plants in order not to reach the $50 \%$ threshold. When modeling the EU policy we assume that the closure rule in strategically ineffective, so free allocation to existing firms is, economically, a lump-sum transfer that does not interfere with the investment decision.

For new installations (which includes capacity extensions in existing plants), the free allowances are provided from the New Entrants Reserve. Given the lack of historical production data for new installations, the preliminary allocation of allowances is calculated by multiplying the benchmark by the installation's capacity (or capacity increase) and a standard capacity utilization factor. Using Table 1, it amounts to subsidizing investment by 15 $€ / \mathrm{t}$ which is one third of the investment $\operatorname{cost}(45 € / \mathrm{t})$.

To sum up, we will model allowance allocation in the EU-ETS as a lump-sum transfer for existing plants plus free allowances for new installations, proportional to the installation's capacity. 


\subsection{Scenarios}

For completeness we shall consider six scenarios:

1. No-Policy: no climate policy.

2. Auction: full auctioning, auction proceeds are not transferred to the cement sector.

3. NER: New Entrant Reserve, i.e. free allocation for new plants, no free allowances (i.e. auctioning) for the other plants. Every new plant receives the same number of allowances per unit of production capacity.

4. EU-ETS: new entrants reserve as in NER plus a lump-sum allowance transfer for existing plants (cf. section 4.2). The lump-sum transfer is based on the EU-ETS benchmark (0.766 tonne $\mathrm{CO}_{2} /$ tonne clinker) times the production of year 2007 (Table 1) minus the capacity of the new plants associated with this scenario (which substitute inefficient old plants). The scenarios NER and EU-ETS are identical except for the distributional outcomes.

5. OBA (Output-Based Allocation): for every tonne of grey clinker produced in the EU, firms receive a given number of allowances. The standard academic approach to OBA is to use as a benchmark the actual emission rate of home plants after abatement (i.e. 0.758 tonne $\mathrm{CO}_{2} /$ tonne clinker, cf. Table 6 ). This scenario is denoted $\mathrm{OBA}^{0}$. As we shall prove later on it turns out that our optimal policy (assuming out border adjustment) would be an OBA policy but with a different benchmark (0.284 tonne $\mathrm{CO}_{2} /$ tonne clinker). This scenario is denoted OBA*.

6. BTA (border adjustment with full auctioning): To be allowed to import into the EU, firms have to pay the $\mathrm{CO}_{2}$ price times an adjustment factor. The optimal BTA policy is based on a benchmark corresponding to the emission rate of foreign plants, assumed 
to be equal to 0.852 tonne $\mathrm{CO}_{2}$ /tonne clinker (cf. Table 1 ). This scenario is denoted BTA*.

\subsection{Results}

We proceed as follows. The optimal policy is characterized, then we compare the various scenarios in terms of welfare, investment and production, price and revenues, emissions and leakage.

\subsubsection{The optimal policy}

As mentioned in section 4.2 our EU calibration corresponds to Case C in corollary 2 (section 4.1). The optimal couple of subsidies satisfies:

$$
\begin{aligned}
& s_{h} / \sigma=u_{f} \frac{b}{b+\gamma_{f}}=.284 \mathrm{tCO}_{2} / \mathrm{t} \text { clinker } \\
& s_{k}=0 \text {. }
\end{aligned}
$$

This means that the optimal policy is OBA*. It is a pure output based scheme with a credit allowance at $5.7 € / \mathrm{t}$ clinker. This result is driven by two factors: imports occur in all states of demand and new plants are always saturated. This explains why capacity based allocation has no bite.

Second, the actual level of the optimal output based rate is at $5.7 € / \mathrm{t}$ clinker (versus $15.3 € / \mathrm{t}$ with the EU-ETS). This is quite low and comes from the factor $b /\left(b+\gamma_{f}\right)=1 / 3$ which depends on the convexity of the imports cost and the price elasticity of demand. 


\subsubsection{Expected Welfare}

Figure 3 depicts the expected welfare variation compared to the No-Policy scenario, in percentage. To highlight the discussion, welfare for each class of scenario is drawn as a function of the allowance allocation or border adjustment per tonne of clinker. As expected, the welfare maximizing policy is BTA*. The associated curve is flat on the top so with a lower adjustment set at the level of the EU benchmark, $0.766 \mathrm{t} \cdot \mathrm{CO}_{2} / \mathrm{t}$. clinker, as proposed by Monjon and Quirion (2010), welfare would be almost as high.

Although less efficient than border adjustment, OBA brings a higher welfare than Auctioning if not too generous, the optimal allocation being for OBA*. NER \& EU-ETS have the same impact as Auctioning if the allocation rate per tonne of clinker capacity installed is quite low, because no investment in new plants takes place anyway, which is also the case under Auctioning. If the allocation rate is higher than $0.204 \mathrm{CO}_{2} / \mathrm{t}$. clinker, new capacity is installed and the impact on welfare is strongly negative. To sum up, welfare with OBA* would be only $0.7 \%$ lower than with BTA* but $5 \%$ higher than with EU-ETS.

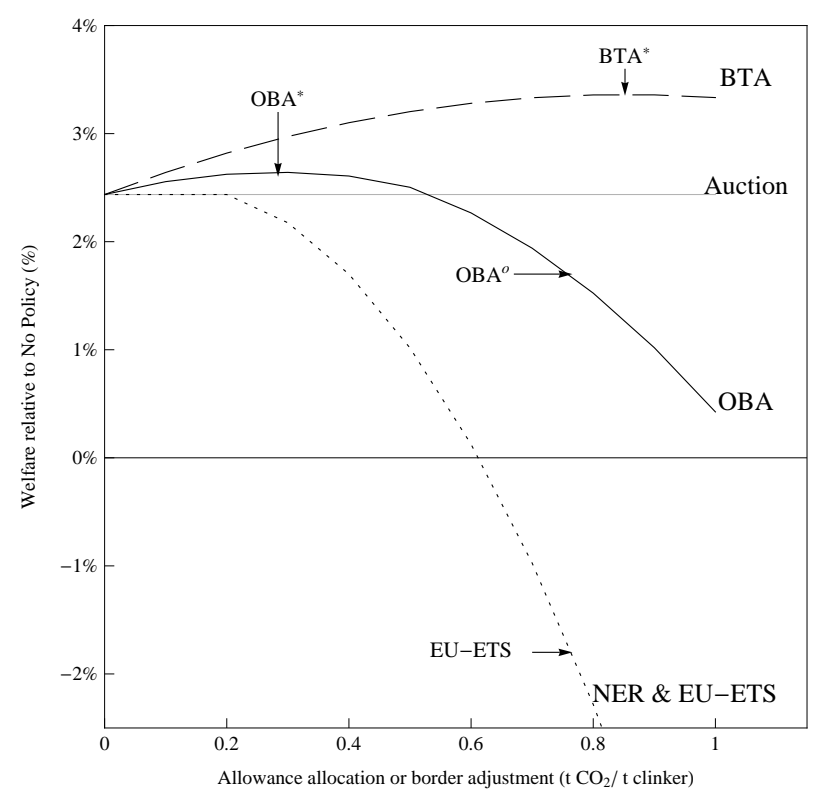

Figure 3: Welfare compared to No-Policy. 


\subsubsection{Investment and production}

Table 2 gives the investment in new capacity and, for each demand state, production from new plants and old plants as well as imports. Note that the investment in new plants would jump from $20 \mathrm{Mt}$ with No-Policy to $79 \mathrm{Mt}$ with EU-ETS or NER, would remain almost unaffected with $\mathrm{OBA}^{0}(17 \mathrm{Mt})$ while there would be no investment with the other scenarios. The EU-ETS or NER schemes would trigger an over-investment in productive capacity in Europe (a point emphasized by Ellerman, 2008, for NER in the electricity sector).

\begin{tabular}{|l|l|l|l|c|l|}
\hline No-Policy & Auction & \multicolumn{2}{|c|}{ OBA } & EU-ETS & BTA* $^{*}$ \\
\cline { 3 - 4 } & & OBA $^{*}$ & OBA $^{0}$ & \& NER & \\
\hline
\end{tabular}

\begin{tabular}{l||c|c|c|c|c|c|}
\hline Investment & 20 & 0 & 0 & 17 & 79 & 0 \\
\hline
\end{tabular} Low demand
\begin{tabular}{|l|c|c|c|c|c|c|}
\hline New plants & 20 & 0 & 0 & 17 & 79 & 0 \\
\hline Old plants & 140 & 124 & 133 & 140 & 79 & 133 \\
\hline Imports & 10 & 22 & 19 & 11 & 11 & 7 \\
\hline \hline Total & 170 & 146 & 152 & 168 & 168 & 141 \\
\hline
\end{tabular}

High demand

\begin{tabular}{|l||c|c|c|c|c|c|}
\hline New plants & 20 & 0 & 0 & 17 & 79 & 0 \\
\hline Old plants & 220 & 204 & 213 & 220 & 159 & 213 \\
\hline Imports & 30 & 42 & 39 & 31 & 31 & 27 \\
\hline \hline Total & 270 & 246 & 252 & 268 & 268 & 241 \\
\hline
\end{tabular}

Table 2: Investment, production and imports in low and high demand states in Mt

\subsubsection{Price of clinker, firms' profits and public revenues}

For each scenario and each demand state Table 3 gives the price for clinker, the detailed profits from new and old plants and from imports. It also gives the public revenues from permits and the total amount of free allocations. By assumption the expected profit for new plants is zero (expected operating revenues exactly cover investment cost). The level of free allocations for old plants for EU-ETS is calculated as the unit carbon price $(20 € / \mathrm{t})$ times the production of year 2007 (240 Mt) minus the investment in new plants (79 Mt) times the 
EU-ETS benchmark (0.766 tonne $\mathrm{CO}_{2}$ /tonne clinker).

Relative to No Policy, on average, firms' profit increases by $22 \%$ with EU-ETS and decreases by $7 \%$ with OBA*. The price of clinker is lower with NER \& EU-ETS than with OBA*. This is so because new capacity creates a larger supply, a mechanism which is stronger than the increase in supply of existing plants generated by the output-based allocation with OBA* As expected there would be almost no changes with $\mathrm{OBA}^{0}$. BTA* would lead to significant price increase and profits decrease (due to the price signal). Qualitatively these results are in line with the literature. The important thing to note is the very substantial increase in firms' profits with EU-ETS relative to $\mathrm{OBA}^{*}(+22 \%$ vs $-7 \%)$ obtained through a decrease in public revenues of $€ 3$ billion (- $1433 \mathrm{M} €$ versus 1.644M $€$ )..$^{9}$ The negative figure for public revenue in the EU-ETS scenario should not be interpreted as direct subsidies to the cement sector, but as the value of the allowances sold by the cement industry to other sectors (mainly electricity).

\subsubsection{Emissions and Leakage}

A standard criterion used in the literature to compare policies is the leakage-to-reduction ratio, or leakage ratio, i.e. the increase in emissions in foreign countries divided by the decrease in emissions in the EU. The results are given in Table 4. The ratio reaches $22 \%$ under Auctioning, less than the values obtained by Demailly and Quirion (2006) as well as by Ponssard and Walker (2008) but more than those obtained by Monjon and Quirion (2011a, 2011b). With $\mathrm{BTA}^{*}$ the ratio is negative (i.e. foreign emissions decrease). This negative leakage rate also appears in many other simulations of border adjustments (cf. Demailly and Quirion, 2008, for cement, or Branger and Quirion, 2014, for a meta-analysis of recent studies beyond cement). The explanation is that less clinker is exported into the EU than under No-Policy.

\footnotetext{
${ }^{9}$ With a completely different methodology, Martin et al. (2012) found an overcompensation of $€ 6.7$ billion for all sectors covered by the EU-ETS.
} 
Low demand

\begin{tabular}{|l|l|l|l|l|l|l|}
\hline No-Policy & Auction & \multicolumn{2}{|c|}{ OBA } & NER & EU-ETS & BTA* $^{*}$ \\
\cline { 3 - 4 } & & OBA $^{*}$ & OBA $^{0}$ & & & \\
\hline
\end{tabular}

\begin{tabular}{l|c|c|c|c|c|c|c|c|}
\hline Price $(€ / \mathrm{t})$ & 60 & 72 & 69 & 61 & 61 & 61 & 75 \\
\begin{tabular}{|l|c|c|c|c|c|c|c|}
\hline - old plants \\
- new plants
\end{tabular} & 2450 & 1913 & 2227 & 2450 & 775 & 3995 & 2227 \\
\hline - from & -200 & 0 & 0 & -170 & -788 & -788 & 0 \\
\hline - foreign plants & 50 & 244 & 178 & 60 & 59 & 59 & 28 \\
\hline Total profits & 2300 & 2158 & 2404 & 2341 & 46 & 3266 & 2255 \\
\hline \hline Public revenue & 0 & 1876 & 1265 & 0 & 1181 & -2039 & 2151 \\
\hline Free allocation & 0 & 0 & 758 & 2122 & 1207 & 4427 & 0 \\
\hline
\end{tabular}

\section{High demand}

\begin{tabular}{|l|l|l|l|l|l|l|l|}
\hline Price $(€ / \mathrm{t})$ & 80 & 92 & 89 & 81 & 81 & 81 & 95 \\
\hline
\end{tabular}

Profits $(\mathrm{M} €)$ from

\begin{tabular}{|l|c|c|c|c|c|c|c|}
\hline - old plants & 6050 & 5188 & 5696 & 6050 & 3149 & 6369 & 5696 \\
\hline - new plants & 200 & 0 & 0 & 170 & 788 & 788 & 0 \\
\hline - foreign plants & 450 & 886 & 754 & 480 & 476 & 476 & 377 \\
\hline Total profits & 6700 & 6073 & 6450 & 6700 & 4412 & 7632 & 6074 \\
\hline \hline Public revenue $(\mathrm{M} €)$ & 0 & 3088 & 2024 & 0 & 2394 & -826 & 3704 \\
\hline Free allocation $(\mathrm{M} €)$ & 0 & 0 & 1212 & 3335 & 1207 & 4427 & 0 \\
\hline
\end{tabular}

\section{Average}

\begin{tabular}{|l|c|c|c|c|c|c|c|}
\hline Profits old plants $(\mathrm{M} €)$ & 4250 & 3551 & 3961 & 4250 & 1962 & 5182 & 3961 \\
\hline Profit vs No Policy(\%) & & $-16 \%$ & $-7 \%$ & $0 \%$ & $-54 \%$ & $22 \%$ & $-7 \%$ \\
\hline Public revenue (M€) & 0 & 2481 & 1644 & 0 & 1787 & -1433 & 2928 \\
\hline Free allocations $(\mathrm{M} €)$ & 0 & 0 & 985 & 2729 & 1207 & 4427 & 0 \\
\hline
\end{tabular}

Table 3: Profits, Public revenue and Free Allocation 
The comparison between OBA* $(19 \%)$, EU-ETS $(3 \%)$ and $\mathrm{OBA}^{0}(4 \%)$ suggests that OBA* performs poorly. But this comparison would be misleading! Indeed, as reported in Table 4 the level of $\mathrm{CO}_{2}$ emissions arising from EU consumption (including imports) is lower with OBA* (156 Mt) than with EU-ETS (167 Mt) or with OBA ${ }^{0}$ (again $167 \mathrm{Mt}$ ). This discussion suggests that the leakage-to-reduction ratio is a bad indicator of the relative merits of each scenario, with respect to both their efficiency and to their environmental impact. ${ }^{10}$ This will be confirmed by the subsequent welfare analysis.

\begin{tabular}{|c|c|c|c|c|c|c|}
\hline & \multirow[t]{2}{*}{ No-Policy } & \multirow[t]{2}{*}{ Auction } & \multicolumn{2}{|c|}{ OBA } & \multirow{2}{*}{$\begin{array}{l}\text { EU-ETS } \\
\& \text { NER }\end{array}$} & \multirow[t]{2}{*}{$\mathrm{BTA}^{*}$} \\
\hline & & & $\mathrm{OBA}^{*}$ & $\mathrm{OBA}^{0}$ & & \\
\hline \multicolumn{7}{|c|}{ Emissions (Mt) } \\
\hline $\begin{array}{l}\text { from domestic } \\
\text { production }\end{array}$ & 172 & 124 & 131 & 149 & 150 & 131 \\
\hline from imports & 17 & 27 & 25 & 18 & 18 & 15 \\
\hline Total & 189 & 151 & 156 & 167 & 167 & 146 \\
\hline $\begin{array}{l}\text { Leakage } \\
\text { ratio }(\%)\end{array}$ & - & 22 & 19 & 4 & 3 & -5 \\
\hline
\end{tabular}

Table 4: Leakage to reduction ratio and Emissions averaged over each demand state.

\section{Conclusion}

This paper provides an original setting to analyze the design of allocation schemes for energy intensive internationally traded industries. When neither a global carbon tax nor a border trade adjustment is politically feasible, free allocation policies have been considered to mitigate leakage and competitiveness issues. Giving due attention to the impact of short term capacity constraints on the import pressure, our analysis allows for the determination of the socially optimal combination of output and capacity based allocations.

\footnotetext{
${ }^{10}$ The comparison of leakage ratios makes more sense if the abatement in the EU is kept constant across scenarios. In our partial analysis only emissions related to the cement industry are considered. With an emissions permits market an increase in the emissions from cement production would be offset by a reduction of the emissions in other sectors via an increase in the permit price. From a welfare perspective it would eventually call for a relaxation of the global cap in order to realign the permit price with the emission marginal cost.
} 
The case of the EU cement sector is discussed in view of our results. Assuming a range of demand uncertainty similar to the one observed in the years 2007-2012 and a $\mathrm{CO}_{2}$ price of $20 € / \mathrm{t} \mathrm{CO}_{2}$, we conclude that the policy that is to be implemented for years 2013-2020 will induce a welfare loss of approximately $5 \%$ relative to the optimal policy and increase profits in the cement industry by almost 1 billion euros per year compared to a scenario without climate policy.

Our model suggests directions in which the current scheme may be improved, such as going to output based free allocations with a relatively low benchmark. It may be interesting to introduce industry specificities such as the oligopolistic structure, the role of geography, or of multi plant ownership, nor a proper dynamic schedule to allow for the explicit lifetime of cement plants to test the robustness of our results. A preliminary analysis has been made regarding the role of geography. In spite of its limitations, we believe that our analysis brings a valid argument to question the current EU-ETS scheme for 2013-2020. It also points out the intrinsic difficulty of relying on a uniform instrument in an industry in which the vulnerability to imports is quite heterogeneous across the various European regions.

From a more methodological standpoint we think that our framework could be extended in three directions so as to enlarge its applicability. First, the analysis may be embedded into a multi-sector ETS with an endogenous emissions price. The rate of capacity and/or output based free allocations will affect not only the emissions in the sector directly concerned but also in other sectors (e.g. the electricity sector). It would be interesting to explore this interdependence and the effect on the choice of the emissions cap. Second, rather than being confined to a home market subject to import, we may consider a set of interconnected markets with local demand and production facilities. In the short term, leakage would depend on short term demand and existing capacity constraints. Firms would locate their investment based on national demand trends and national regulations. These investment strategies might generate a long term leakage, depending on the carbon price and on the 
allocation mechanism. A better understanding of these two forms of leakage would be helpful to analyze the impacts of existing regulatory policies and design better ones in a world of asymmetric carbon prices. Third, and in particular with respect to the role of investment, more general specifications may be worth exploring.

\section{References}

[1] BCG (Boston Consulting Group), 2008. Assessment of impact of 2013-2020 ETS Proposal on the European Cement Industry. Methodology and assumptions. November 6. Report for Cembureau.

[2] Böhringer, C., C. Fischer and K.E. Rosendahl, 2010, The Global Effects of Subglobal Climate Policies, The B.E. Journal of Economic Analysis \& Policy 10 (2) (Symposium), Article 13.

[3] Böhringer, C., J.C. Carbone, T.F. Rutherford, 2012. Unilateral climate policy design: Efficiency and equity implications of alternative instruments to reduce carbon leakage. Energy Economics 34(S2): S208-S217

[4] ref: Branger, F., P. Quirion, 2014. Would Border Carbon Adjustments prevent carbon leakage and heavy industry competitiveness losses? Insights from a meta-analysis of recent economic studies. Ecological Economics 99: 29-39.

[5] Cembureau, 2007. Activity Report, Brussels.

[6] Cembureau, 2009. Activity Report, Brussels.

[7] Demailly, D. and P. Quirion, 2006. CO2 abatement, competitiveness and leakage in the European cement industry under the EU-ETS: grandfathering vs. output-based allocation, Climate Policy, 6 (1), p. 93-113. 
[8] Demailly, D. and P. Quirion, 2008, Leakage from Climate Policies and Border Tax Adjustment: Lessons from a Geographic Model of the Cement Industry? in R. Guesnerie and H. Tulkens, (ed.), The Design of Climate Policy, papers from a Summer Institute held in Venice, Boston: The MIT Press, CESifo Seminar Series.

[9] D. Demailly \& P. Quirion The Competitiveness Impact of CO2 Emissions Reduction in the Cement Sector. Report for the OECD.

http://www.oecd.org/officialdocuments/displaydocument/?doclanguage= en\&cote $=$ com/env/epoc/ctpa/cfa(2004)68/final

[10] Ecofys, Fraunhofer Institute for Systems and Innovation Research, Öko-Institut, 2009. Methodology for the free allocation of emission allowances in the EU-ETS post 2012. Sector report for the cement industry.

[11] Ellerman, A.D., 2008. New Entrant and Closure Provisions: How do they Distort?. Energy Journal, 29 (Special Issue).

[12] Ellerman, A.D. and Convery, F.J. and De Perthuis, 2010, Pricing carbon: The European union emissions trading scheme, Cambridge University Press.

[13] Exane BNP Paribas, 2006. Building Materials Equity Research Report. 20 March, http: //www. exanebnpparibas-equities.com.

[14] Fischer, C. and Alan K. Fox, 2012, Comparing policies to combat emissions leakage: Border carbon adjustments versus rebates, Journal of Environmental Economics and Management, 64(2): 199-216.

[15] Fowlie, M., Reguant, M., Ryan, S.P., 2012, Market-based emissions regulation and industry dynamics., National Bureau of Economic Research, w18645. 
[16] Grubb, M., Cooper, S. 2011. Revenue Dimension of the EU-ETS Phase III. Climate Strategies, 12 May, http://www.climatestrategies.org/research/our-reports/ category/61/313.html.

[17] Golombek, R., S. A. C. Kittelsen and K. E. Rosendahl, 2011, Price and welfare effects of emission quota allocation, Energy Economics 36: 568-580.

[18] Holland, S. P. (2012). Emissions taxes versus intensity standards: Second-best environmental policies with incomplete regulation. Journal of Environmental Economics and Management, 63(3), 375-387.

[19] Hood, C. 2010. Reviewing existing and proposed emission trading systems. IEA, http: //www.iea.org/papers/2010/ets_paper2010.pdf.

[20] Hourcade, J.-C., D. Demailly, K. Neuhoff and M. Sato, 2007. Differentiation and dynamics of EU-ETS competitiveness impacts. Climate Strategies report, http://www. climatestrategies.org/research/our-reports/category/6/37.html.

[21] Kettner, C., A. Koppl and S. Schleicher, 2008. EU Emissions Trading Scheme: The phase 1 performance. WIFO, Austrian Institute for Economic Research. Vienna. www. wifo.at.

[22] Martin, R. and M. Muûls and L.B. de Preux and Wagner, U.J., 2012, Industry Compensation under Relocation Risk: a Firm-Level Analysis of the Eu Emissions Trading Scheme, working paper, http://ssrn.com/abstract=2033683.

[23] Meunier, G. and J.-P. Ponssard, 2014. Capacity decisions with demand fluctuations and carbon leakage. Resource and Energy Economics, 36, 436-454.

[24] Monjon, S. and P. Quirion, 2010. How to design a border adjustment for the European Union Emissions Trading System?, Energy Policy, 38(9): 5199-5207. 
[25] Monjon, S. and P. Quirion, 2011a. Addressing leakage in the EU-ETS: Border adjustment or output-based allocation?, Ecological Economics, 70(11): 1957-1971

[26] Monjon, S. and P. Quirion, 2011b. A border adjustment for the EU-ETS: Reconciling WTO rules and capacity to tackle carbon leakage, Climate Policy, 11(5): 1212-1225.

[27] Neuhoff, K., K. K. Martinez, M. Sato, 2006. Allocation, incentives and distortions: The impact of EU-ETS emission allowance allocations to the electricity sector. Climate Policy, 6: 73-91.

[28] Ponssard, J.-P. and N. Walker, 2008. EU emissions trading and the cement sector: a spatial competition analysis. Climate Policy 8(5): 467-493

[29] Quirion, P., 2009. Historic versus output-based allocation of GHG tradable allowances: a survey. Climate Policy, 9: 575-592.

[30] Quirion, P., S. Healy and K. Schumacher, 2012. Modelling the allowance allocation method of the EU-ETS: an application to the cement industry. Climate Strategies Report, http://www.climatestrategies.org/research/our-reports/ category/60/344.html.

[31] Röller, L.H. and F. Steen, 2006. On the Workings of a Cartel: Evidence from the Norwegian Cement Industry. American Economic Review, 96(1): 321-338. http: //minerals.usgs.gov/minerals/pubs/commodity/cement/index.html\#mcs

[32] Wooders P., and A.Cosbey, 2010. Issues for the WTO Climate-linked tariffs and subsidies: Economic aspects (competitiveness \& leakage). Thinking Ahead on International Trade (TAIT), 2nd Conference Climate Change, Trade and Competitiveness. 
[33] Zhao, J. B. F. Hobbs and J.-S. Pang, 2010. Long-Run Equilibrium Modeling of Emissions Allowance Allocation Systems in Electric Power Markets. OPERATIONS RESEARCH. 58(3): 529-548.

\section{Appendix A: Proof of proposition 1}

With the expression of expected welfare in (2) written as a function of $s_{h}$ and $k$, the objective of the benevolent regulator is to maximize $W\left(s_{h}, k\left(s_{h}, s_{k}\right)\right)$. The subsidies $s_{h}$ and $s_{k}$ are used to influence home production and capacity. The influence of the subsidy $s_{k}$ on home production is only indirect via the choice of capacity. There is at least one couple of optimal subsidies, because $W$ is continuous, bounded and the choice set of subsidies could be restricted to a compact set. The couple of optimal subsidies satisfies the couple of first order conditions:

$$
\frac{\partial W}{\partial k} \frac{\partial k}{\partial s_{k}}=0 \text { and } \frac{\partial W}{\partial s_{h}}+\frac{\partial W}{\partial k} \frac{\partial k}{\partial s_{h}}=0
$$

which are equivalent to the couple of equations:

$$
\frac{\partial W}{\partial k}=0 \text { and } \frac{\partial W}{\partial s_{h}}=0 .
$$

The problem is therefore similar to the choice of $s_{h}$ and $k$ to maximize $W\left(s_{h}, k\right)$.

The derivatives of welfare in a state $\theta$ (cf eq. 1) with respect to $s_{h}$ for a given $k$ is, using the first order conditions (5) and (6),

$$
\left[\frac{\partial w}{\partial q_{h}}+\frac{\partial w}{\partial q_{f}} \frac{\partial \psi_{f}}{\partial q_{h}}\right] \frac{\partial q_{h}}{\partial s_{h}}=\left(-s_{h}-\sigma u_{f} \frac{\partial \psi_{f}}{\partial q_{h}}\right) \frac{\partial q_{h}}{\partial s_{h}} .
$$


Therefore, the first order condition is :

$$
\mathbb{E}\left[\left(-s_{h}-\sigma \frac{\partial \psi_{f}}{\partial q_{h}}\right) \frac{\partial q_{h}}{\partial s_{h}}\right]=0
$$

and the expression (10) follows. Concerning the choice of $s_{k}$, from the first order conditions satisfied by productions, (5) and (6), and by the capacity (8) one gets

$$
\begin{aligned}
\frac{\partial W}{\partial k} & =\mathbb{E}\left[\left(\frac{\partial w}{\partial q_{h}}+\frac{\partial w}{\partial q_{f}} \frac{\partial \psi_{f}}{\partial q_{h}}\right) \frac{\partial q_{h}}{\partial k}\right]-\mathbb{E}\left[\frac{\partial C_{h}\left(q_{h}, k\right)}{\partial k}\right]-c_{k} \\
& =\mathbb{E}\left[\left(-s_{h}+\sigma u_{f} \frac{\partial \psi_{f}}{\partial q_{h}}\right) \frac{\partial q_{h}}{\partial k}\right]-s_{k}
\end{aligned}
$$

the expression (11) follows.

\section{Appendix B: The specification and the proof of Corol- lary (2)}

\section{Appendix B.1: Equilibrium}

Let us first describe the short-term equilibrium. In a demand states $\theta$, there is a unique couple of non-negative productions $q_{h}$ and $q_{f}$ such that $q_{h}>0$ and $p=\partial C_{h} / \partial q_{h}$, and, concerning foreign production, either $q_{f}=0$ and $p<c_{f}$, or $q_{f}>0$ and $p=\partial C_{f} / \partial q_{f}$. This is so because $c_{f}>c_{h}+\sigma u_{h}-s_{h}$.

Three situations can occur whether the home production is smaller or larger than $k$, and whether the foreign production is positive or null. Given the assumption $c_{f}>c_{h}+\sigma u_{h}-s_{h}$ there is no import if $q_{h}<k$. Both productions are increasing with respect to $\theta$ so there are two thresholds $\theta_{1}$ and $\theta_{2}$ such that $q_{h}<k$ if and only if $\theta<\theta_{1}$ and $q_{f}>0$ if and only if 
$\theta>\theta_{2}$.

1. If $\theta<\theta_{1}, q_{h}<k$, and $p=c_{h}+\sigma u_{h}-s_{h}$ and

$$
q_{h}=\left[(a+\theta)-\left(c_{h}+\sigma u_{h}-s_{h}\right)\right] / b .
$$

2. If $\theta_{1} \leq \theta \leq \theta_{2}, q_{h}=k, q_{f}=0$, and $p=c_{h}+\sigma u_{h}-s_{h}+\gamma_{h}\left(q_{h}-k\right)$ so

$$
q_{h}=\left[(a+\theta)-\left(c_{h}+\sigma u_{h}-s_{h}-\gamma_{h} k\right)\right] /\left[b+\gamma_{h}\right]
$$

3. If $\theta_{2}<\theta$, then $q_{f}>0$ and $p=c_{f}+\gamma_{f} q_{f}$ so

$$
\psi_{f}=\left[a+\theta-b q_{h}-c_{f}\right] /\left[b+\gamma_{f}\right]
$$

and injecting this expression into the first order condition $p=c_{h}+\sigma u_{h}-s_{h}+\gamma_{h}\left(q_{h}-k\right)$ gives

$$
q_{h}=\left[(a+\theta)+\frac{b}{\gamma_{f}} c_{f}-\left(1+\frac{b}{\gamma_{f}}\right)\left(c_{h}+\sigma u_{h}-s_{h}-\gamma_{h} k\right)\right]\left[b+\gamma_{h}\left(1+\frac{b}{\gamma_{f}}\right)\right]^{-1}
$$

The expressions of the threshold states could be found by noting that $p\left(k, \theta_{1}\right)=c_{h}+$ $\sigma u_{h}-s_{h}$ and $p\left(q_{h}, \theta_{2}\right)=c_{f}$ with $q_{h}$ given by the expression 30 . These two equations give an expressions of the thresholds as a function of the capacity. In the long-term the capacity is endogenous and the thresholds are functions of the parameters.

In the long-run, (if there is a positive investment) the capacity chosen satisfies the equation: $\lambda\left(p\left(k, \theta^{-}\right)-c_{h}-\sigma u_{h}+s_{h}\right)+(1-\lambda)\left(p\left(k, \theta^{+}\right)-c_{h}-\sigma u_{h}+s_{h}\right)-c_{k}+s_{k}=0$. There is a unique solution to this equation (the prices are decreasing w.r.t. $k$ ). The average price should be equal to the long-run marginal cost $c_{h}+\sigma u_{h}-s_{h}+c_{k}-s_{k}$. The explicit expression of the equilibrium capacity depends upon the associated short-term equilibriums. There are 
5 possible situations, two in which the firm never imports, and the three situations of interest depicted in Figure (1) in which imports occur in the high demand state $\theta^{+}$.

The following conditions on the import $\operatorname{costs} c_{f}$ and the range of uncertainties determine in which situation the market is, in the long-run (with the equilibrium capacity). It corresponds to a situation without regulation $\left(\sigma=s_{h}=s_{k}=0\right)$ to alleviate notations, the regulations components can be added to the costs components $c_{h}$ and $c_{k}$.

- If $c_{f} \geq \min \left\{c_{h}+(1-\lambda) \frac{\gamma}{b+\gamma}\left(\theta^{+}-\theta^{-}\right), \frac{c_{k}}{\lambda}+c_{h}\right\}$, the firm never imports and either produces at full capacity or is in excess capacity in the low demand states (the two subcases are not detailed here).

- Otherwise, if $c_{f}<\min \left\{c_{h}+(1-\lambda) \frac{\gamma}{b+\gamma}\left(\theta^{+}-\theta^{-}\right), \frac{c_{k}}{\lambda}+c_{h}\right\}$ the firm imports in the high demand state $\theta^{+}$and

Case A: if $\theta^{+}-\theta^{-}>\frac{c_{k}}{\lambda}\left(1+\frac{1}{\gamma_{h}}+\frac{1}{\gamma_{f}}\right)-\frac{b}{\gamma_{f}}\left(c_{f}-c_{h}\right)$, the firm produces less than its capacity in the low demand state;

Case B: if $\frac{c_{k}}{\lambda}\left(1+\frac{1}{\gamma_{h}}+\frac{1}{\gamma_{f}}\right)-\frac{b}{\gamma_{f}}\left(c_{f}-c_{h}\right)<\theta^{+}-\theta^{-}<\left[\left(c_{k}+c_{h}\right)-c_{f}\right] \frac{1}{\lambda}\left(1+\frac{1}{\gamma_{h}}+\frac{1}{\gamma_{f}}\right)$, the firm does not import and produces more than its new capacity in the low demand state;

Case C: if $\theta^{+}-\theta^{-}<\left[\left(c_{k}+c_{h}\right)-c_{f}\right] \frac{1}{\lambda}\left(1+\frac{1}{\gamma_{h}}+\frac{1}{\gamma_{f}}\right)$, the firm imports in both states.

The Figure (4) depicts how the range of uncertainty and the import costs determine in which situation the market is. 


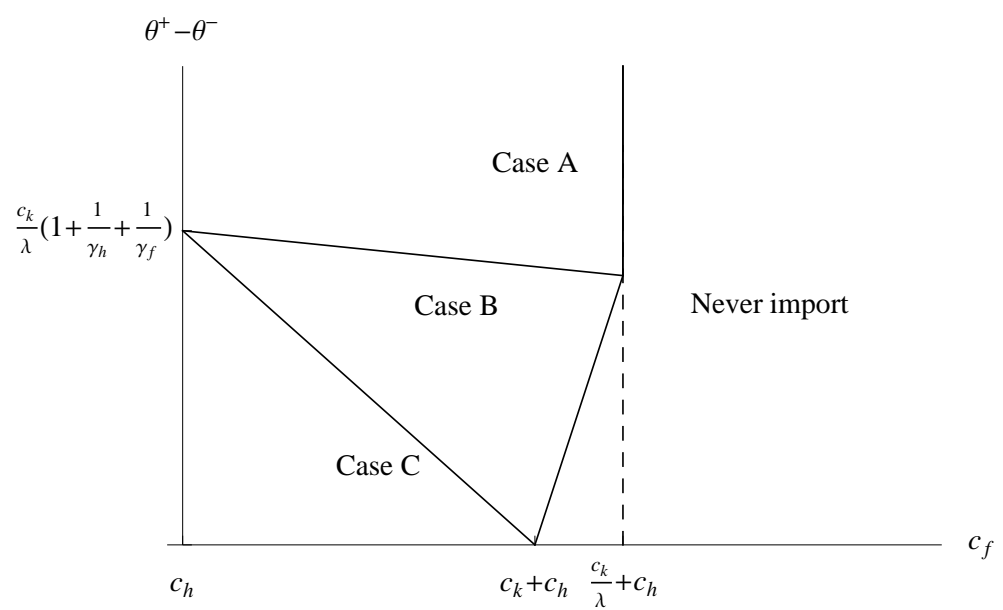

Figure 4: The different cases of Corollary 2 as a function of parameter values.

\section{Appendix B.2: Proof of Corollary 2}

We proceed in two steps. We first determine the sensitivity of imports and the effects of the production subsidy and of the capacity on the home production Then we use the expressions of Prospotiion 1.

With the expressions of the home production (29), (30) and (32), and the expression of the imports function $\psi_{f}(31)$ we have the following derivatives:

\begin{tabular}{c|c|c|c|} 
& $\theta<\theta_{1}$ & $\theta_{1}<\theta<\theta_{2}$ & $\theta_{2}<\theta$ \\
\hline$-\frac{\partial \psi_{f}}{\partial q_{h}}$ & 0 & 0 & $b /\left(b+\gamma_{f}\right)$ \\
\hline$\frac{\partial q_{h}}{\partial s_{h}}$ & $1 / b$ & $1 /\left(b+\gamma_{h}\right)$ & $1 /\left[\gamma_{h}+b \gamma_{f} /\left(b+\gamma_{f}\right)\right]$ \\
\hline$\frac{\partial q_{h}}{\partial k}$ & 0 & $\gamma_{h} /\left(b+\gamma_{h}\right)$ & $\gamma_{h} /\left[\gamma_{h}+b \gamma_{f} /\left(b+\gamma_{f}\right)\right]$ \\
\hline
\end{tabular}

Table 5: Expressions of the derivatives in a demand state $\theta$.

- Case A: it corresponds to $\theta^{-}<\theta_{1}$ and $\theta^{+}>\theta_{2}$ so from equation 10 and the Table 
(5):

$$
\begin{aligned}
\frac{s_{h}}{\sigma u_{f}} & =\mathbb{E}\left[\frac{\partial \psi_{f}}{\partial q_{h}} \frac{\partial q_{h}}{\partial s_{h}}\right] / \mathbb{E}\left[\frac{\partial q_{h}}{\partial s_{h}}\right] \\
& =\left\{(1-\lambda) \times 0+\lambda \frac{b}{b+\gamma_{f}} /\left[\gamma_{h}+\gamma_{f} \frac{b}{b+\gamma_{f}}\right]\right\} /\left\{(1-\lambda) \frac{1}{b}+\lambda /\left[\gamma_{h}+\gamma_{f} \frac{b}{b+\gamma_{f}}\right]\right\} \\
& =\lambda \frac{b}{b+\gamma_{f}} /\left\{(1-\lambda) \frac{1}{b}\left[\gamma_{h}+\gamma_{f} \frac{b}{b+\gamma_{f}}\right]+\lambda\right\} \\
& =\lambda \frac{b}{b+\gamma_{f}} \frac{1}{(1-\lambda) R_{A}+\lambda} \text { with } R_{A} \text { defined by eq. }
\end{aligned}
$$

and concerning the capacity subsidy, first note that, in that case, $\mathbb{E}\left[-\frac{\partial \psi_{f}}{\partial q_{h}} \frac{\partial q_{h}}{\partial k}\right]=$ $\gamma_{h} \mathbb{E}\left[-\frac{\partial \psi_{f}}{\partial q_{h}} \frac{\partial q_{h}}{\partial s_{h}}\right]$. Injecting this relationship into equation 11 gives

$$
s_{k}=s_{h} \mathbb{E}\left[\gamma_{h} \frac{\partial q_{h}}{\partial s_{h}}-\frac{\partial q_{h}}{\partial k}\right]=s_{h}(1-\lambda) \frac{\gamma_{h}}{b}
$$

- Case B: it corresponds to $\theta_{1}<\theta^{-}<\theta_{2}$ and $\theta^{+}>\theta_{2}$ so

$$
\begin{aligned}
\frac{s_{h}}{\sigma u_{f}} & =\mathbb{E}\left[\frac{\partial \psi_{f}}{\partial q_{h}} \frac{\partial q_{h}}{\partial s_{h}}\right] / \mathbb{E}\left[\frac{\partial q_{h}}{\partial s_{h}}\right] \\
& =\left\{(1-\lambda) \times 0+\lambda \frac{b}{b+\gamma_{f}} /\left[\gamma_{h}+\gamma_{f} \frac{b}{b+\gamma_{f}}\right]\right\} /\left\{(1-\lambda) \frac{1}{b+\gamma_{h}}+\lambda /\left[\gamma_{h}+\gamma_{f} \frac{b}{b+\gamma_{f}}\right]\right\} \\
& =\lambda \frac{b}{b+\gamma_{f}} /\left\{(1-\lambda) \frac{1}{b+\gamma_{h}}\left[\gamma_{h}+\gamma_{f} \frac{b}{b+\gamma_{f}}\right]+\lambda\right\} \\
& =\lambda \frac{b}{b+\gamma_{f}} \frac{1}{(1-\lambda) R_{B}+\lambda} \text { with } R_{B} \text { defined by eq. 19). }
\end{aligned}
$$

and concerning the capacity subsidy, in that case, $\frac{\partial q_{h}}{\partial k}=\gamma_{h} \frac{\partial q_{h}}{\partial s_{h}}$. in both demand states (cf Table 5), so, from (11), $s_{k}=0$.

- Case C: it corresponds to $\theta^{+}>\theta^{-}>\theta_{2}$ so (from Table 5)

$$
\frac{s_{h}}{\sigma u_{f}}=\mathbb{E}\left[\frac{\partial \psi_{f}}{\partial q_{h}} \frac{\partial q_{h}}{\partial s_{h}}\right] / \mathbb{E}\left[\frac{\partial q_{h}}{\partial s_{h}}\right]=\frac{b}{b+\gamma_{f}} \mathbb{E}\left[\frac{\partial q_{h}}{\partial s_{h}}\right] / \mathbb{E}\left[\frac{\partial q_{h}}{\partial s_{h}}\right]=\frac{b}{b+\gamma_{f}}
$$


and concerning the capacity subsidy, in that case, $\frac{\partial q_{h}}{\partial k}=\gamma_{h} \frac{\partial q_{h}}{\partial s_{h}}$. in both demand states (cf Table 5) so, from (11), $s_{k}=0$.

\section{Appendix B.3: Calibration of a No Policy scenario}

A No Policy scenario is used as a counterfactual. This scenario refers to a representative year of the period 2013/2020 11 The demand for that year may be high or low, with equal probability. Prior to that period the EU cement industry invests in some new capacity. Once the demand is known, domestic production (from new and old plants) and imports meet the demand.

This scenario is calibrated using data from 2007 as a high demand year and 2009 as a low demand year (see table 1 part 1). Since the EU-ETS concerns clinker and not cement our numerical values are for clinker using the fact that cement is composed of $78 \%$ of clinker, according to the WBCSD CSI GNR database. ${ }^{12}$

More precisely, we use clinker production from the cement production data provided by the European cement manufacturer association activity reports (Cembureau 2007, 2009). There is no publicly available clinker price data (and no publicly available cement price data at the EU level). We compute a clinker unit value from the UN Comtrade databas $\underbrace{13}$ by dividing the value of EU imports by their volume. This database also provides the volume of imports. As expected, for the peak year 2007 imports are higher relative to domestic production than for the recession year 2009, $11 \%$ versus $6 \%$.

The slope of the demand curve is set at $0.5(€ / \mathrm{t}) / \mathrm{Mt}$, which brings a price elasticity of demand between -0.5 and -1.1 , i.e. in the range of published estimates, whatever the state

\footnotetext{
${ }^{11}$ An alternative interpretation is to consider that we simulate the adoption of EU-ETS 2013-2020 scheme in year 2005, and compare it with several other schemes. The No-Policy scenario then corresponds to what actually happened through 2005 to 2009, under the assumption that the industry had anticipated an uncertain demand corresponding to the high and low demands of the years 2007 and 2009.

12 http://www.wbcsdcement.org/

13 http://comtrade.un.org/db/
} 
of demand and the policy scenario. ${ }^{14}$

The production from new plants is estimated indirectly. Firstly, there is no published estimate of new clinker capacities since Cembureau stopped publishing plant-level data in 2002 15 Secondly, the amount of "new" clinker production capacity obviously depends on the length of the period considered. Hence, the figure retained (20 Mt of yearly production capacity during the period considered) should be taken as illustrative. However, it corresponds roughly to the amount of capacity added in the EU 27 in the last ten years during which Cembureau plant-level data were available, assuming that a clinker kiln has an average yearly capacity of $1 \mathrm{Mt}$.

With these data, we run the model backwards with a zero $\mathrm{CO}_{2}$ price, ${ }^{16}$ in order to find the parameters that are consistent with the above-mentioned data. We proceed in three steps. Step $1, c_{h}$ and $1 / \gamma_{h}$ are obtained through supply and demand equations in both demand states. Step 2, we proceed similarly to get $c_{f}$ and $1 / \gamma_{f}$ introducing imports in these equations. Step 3, $c_{k}$ is obtained using an expected zero profit condition for investment in new capacity. The marginal cost of imports increases from $60 € / \mathrm{t}$ to $80 € / \mathrm{t}$ when imports increase from $10 \mathrm{Mt}$ to $30 \mathrm{Mt}$ corresponding respectively to the low and high demand states. Investment in new plants generates a total (fixed + variable) marginal cost of $70 € / \mathrm{t}(45+25)$ which corresponds to the average clinker price. Producing $100 \mathrm{Mt}$ through old plants would generate a marginal cost of $50 € / \mathrm{t}(25+100 / 4)$ and with $200 \mathrm{Mt}$ it would be $75 € / \mathrm{t}$.

The values of these calibrated parameters are given in Table 1 part $2{ }^{17}$ The parameters

\footnotetext{
${ }^{14}$ Röller and Steen (2006) estimate a short-run elasticity of -0.46 and a long-run elasticity of -1.47 , based on Norwegian data.

15 Admittedly, the US Geological survey (2011) publishes end-year clinker capacities for France, Germany, Italy and Spain, but they cannot be directly used for two reasons. Firstly, we have some doubts on their accuracy because they do not match Cembureau capacity data which were published until 2002. Secondly, the US Geological survey publishes only end-year capacity, which is increased by plant creation but reduced by plant closure, with no possibility to disentangle these two effects.

${ }^{16}$ We abstract from the possible impact from the EU-ETS during those years, given the high level of free allowances and industry behavior based on average rather than marginal carbon price (Ellerman et al. 2010)

${ }^{17}$ Note that annualized fixed cost may seem high in comparison to some estimates in the grey literature (e.g. BCG, 2008, or Exane BNP Paribas, 2006) but they implicitly include a fraction of labor costs, a profit
} 
given in Table 1 part 3 do not concern the No Policy scenario but the scenarios to be studied, since they are linked to emissions and abatement. Three important assumptions are made. Firstly, all EU plants are assumed to have the same specific emissions ${ }^{18}$ and the same stands for all foreign plants, but specific emissions of EU and foreign plants differ. Secondly, the marginal abatement cost curve is assumed to be linear: every extra $€ / \mathrm{t} \mathrm{CO}_{2}$ brings the same extra abatement per tonne of clinker. Thirdly, the abatement cost is assumed to be part of the variable cost, not of the investment cost, which allows a symmetric treatment of new and existing plants and is a common assumption in the literature. Average specific emissions in the EU are taken from the cement sector report which served as a basis to set the benchmark for free allocation in phase III of the EU-ETS (Ecofys et al., 2009). Average specific emissions in the rest of the world are taken from the WBCSD CSI database, and slightly corrected to be more consistent with our figure for EU emissions. The CO2 price is $20 € / \mathrm{t}$. CO2, in line with forecasts for 2020 if the EU GHG target remains at $-20 \%$ compared to 1990 (Grubb and Cooper, 2011) and the parameter of the MAC curve is such that this price reduces specific emissions by ca. $10 \%$.

margin and all the administrative costs incurred by the authorization procedure to operate a new clinker plant in Europe.

${ }^{18}$ Admittedly, some plants emit more than others, with specific emissions in the EU ranging from ca. 750 to ca. $1150 \mathrm{~kg} \mathrm{CO} / \mathrm{t}$ (Ecofys et al., 2009). However, accounting for this heterogeneity in our model would have required heroic assumptions about the correlation between specific emissions and production cost, since no such information is publicly available to our knowledge. 


\begin{tabular}{|l|c|c|}
\hline \multicolumn{2}{|c|}{ Part 1: Data used for calibration of the No Policy scenario } \\
\hline \hline \multicolumn{1}{|c|}{ Variable } & Value & Source \\
\hline Demand curve slope (b) & $0.5(€ / \mathrm{t}) / \mathrm{Mt}$ & Own estimation \\
\hline $\begin{array}{l}\text { Clinker price } \\
\text { (high demand - h.d.) }\end{array}$ & $80 € / \mathrm{t}$ & UN Comtrade (2007) \\
\hline $\begin{array}{l}\text { Clinker price } \\
\text { (low demand - l.d.) }\end{array}$ & $60 € / \mathrm{t}$ & UN Comtrade (2009) \\
\hline $\begin{array}{l}\text { Production from existing } \\
\text { plants (h.d.) }\end{array}$ & $220 \mathrm{Mt} / \mathrm{yr}$ & Cembureau (2007) \\
\hline $\begin{array}{l}\text { Production from existing } \\
\text { plants (l.d.) }\end{array}$ & $140 \mathrm{Mt} / \mathrm{yr}$ & Cembureau (2009) \\
\hline $\begin{array}{l}\text { Production from } \\
\text { new plants }\end{array}$ & $20 \mathrm{Mt} / \mathrm{yr}$ & Own estimation \\
\hline Imports (h.d.) & $10 \mathrm{Mt} / \mathrm{yr}$. & UN Comtrade (2009) \\
\hline Imports (l.d.) & & UN Comtrade (2007) \\
\hline
\end{tabular}

\begin{tabular}{|l|c|}
\hline \multicolumn{2}{|c|}{ Part 2: Parameters calibrated } \\
\hline \hline \multicolumn{1}{|c|}{ Parameter } & Value \\
\hline Expected demand curve intercept $(\mathrm{a})$ & $180 € / \mathrm{t}$ \\
\hline Standard deviation of $\theta$ & $35 € / \mathrm{t}$ \\
\hline Annualized fixed cost of capacity $\left(c_{k}\right)$ & $45 € / \mathrm{t}$ \\
\hline $\begin{array}{l}\text { Operational cost of new plants } \\
\text { and of the least costly existing plant }\left(c_{h}\right)\end{array}$ & $25 € / \mathrm{t}$ \\
\hline price of cheapest import $\left(c_{f}\right)$ & $50 € / \mathrm{t}$ \\
\hline Slope of existing plants supply curve $\left(\gamma_{h}\right)$ & $0.25(€ / \mathrm{t}) / \mathrm{Mt}$ \\
\hline Slope of imports supply curve $\left(\gamma_{f}\right)$ & $1(€ / \mathrm{t}) / \mathrm{Mt}$ \\
\hline
\end{tabular}

\begin{tabular}{|l|c|c|}
\hline \multicolumn{3}{|c|}{ Part 3: Additional parameters used for the other scenarios } \\
\hline \hline \multicolumn{1}{|c|}{ Parameter } & Value & Source \\
\hline $\mathrm{CO}_{2}$ price $(\sigma)$ & $20 € / \mathrm{t}$ & Grubb and Cooper $(2011)$ \\
\hline $\begin{array}{l}\text { Benchmark for free allocation } \\
\text { in the ETS }\end{array}$ & $766 \mathrm{~kg} \mathrm{CO} / \mathrm{t}$ & E.C. $(2010)$ \\
\hline $\begin{array}{l}\text { Specific emissions, EU27 } \\
\left(u_{h} \text { for } \sigma=0\right)\end{array}$ & $858 \mathrm{~kg} \mathrm{CO}_{2} / \mathrm{t}$ & E.C. $(2010)$ \\
\hline $\begin{array}{l}\text { Specific emissions, } \\
\text { rest of the world }\left(u_{f}\right)\end{array}$ & $852 \mathrm{~kg} \mathrm{CO} / \mathrm{t}$ & $\begin{array}{l}\text { WBCSD }+ \\
\text { E. C. }(2010)\end{array}$ \\
\hline MAC curve slope & $0.2 € / \mathrm{kg} \mathrm{CO}_{2}^{\dagger}$ & Own estimation \\
\hline
\end{tabular}

$\dagger$ For $\sigma=20 € / \mathrm{t}$, the emission rate is $u_{h}=758 \mathrm{~kg} \mathrm{CO} 2 / \mathrm{t}$

Table 6: Calibration of the No-Policy scenario and additional parameters 